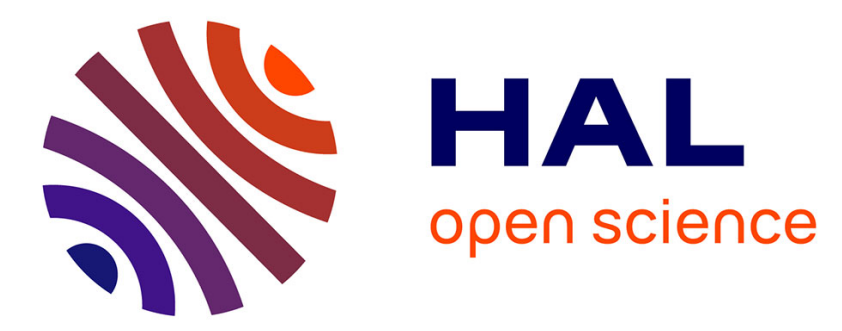

\title{
Investigating wood under thermo-hydromechanical loading at the ring scale using full-field measurements
}

\author{
D. Dang, Rostand Moutou Pitti, E. Toussaint, M. Grédiac
}

\section{To cite this version:}

D. Dang, Rostand Moutou Pitti, E. Toussaint, M. Grédiac. Investigating wood under thermohydromechanical loading at the ring scale using full-field measurements. Wood Science and Technology, 2018, 52 (6), pp.1473 - 1493. 10.1007/s00226-018-1051-9 . hal-01909281

\section{HAL Id: hal-01909281 \\ https://hal.science/hal-01909281}

Submitted on 1 Nov 2018

HAL is a multi-disciplinary open access archive for the deposit and dissemination of scientific research documents, whether they are published or not. The documents may come from teaching and research institutions in France or abroad, or from public or private research centers.
L'archive ouverte pluridisciplinaire HAL, est destinée au dépôt et à la diffusion de documents scientifiques de niveau recherche, publiés ou non, émanant des établissements d'enseignement et de recherche français ou étrangers, des laboratoires publics ou privés. 


\title{
Investigating wood under thermo-visco-hydro-mechanical loading at the ring scale using full-field measurements
}

\author{
D. Dang ${ }^{1}$, R. Moutou Pitti ${ }^{1,2^{*}}$, E. Toussaint ${ }^{1}$, M. Grédiac ${ }^{1}$ \\ ${ }^{1}$ Université Clermont Auvergne, CNRS, Institut Pascal, F-63000, Clermont-Ferrand, France \\ ${ }^{2}$ CENAREST, IRT, 14070, Libreville, Gabon \\ *E-mail : rostand.moutou_pitti@uca.fr
}

\begin{abstract}
The thermo-visco-hydro-mechanical (TVHM) loading of Abies Alba Mills (white fir of Massif Central) is investigated in this paper. A full-field measurement technique, namely the grid method, is used in the experiments in order to observe heterogeneities and to measure strain fields in the annual growth rings. This enables the investigation of the effects of moisture content changes on the strain of latewood and earlywood during creep and recovery. The tested specimens are first conditioned to a given moisture content. Each of them is then subjected to a compression test and regularly removed in order to measure the moisture content. A positioning system is developed to ensure the consistent location of each specimen with respect to the camera. Before loading, images are taken using a CCD camera to highlight the impact of moisture conditioning. Images are also acquired during the loading steps, and between each recovery step after complete unloading. All the strain maps are determined with respect to a reference image taken either before the water conditioning of the specimen or before loading. During the experiments, strain gradients clearly appear between latewood and earlywood, highlighting the variability of the mechanical properties at the ring scale. The effect of moisture content changes on the mechanical behavior of wood at the ring scale is evidenced and discerned.
\end{abstract}

Keywords : creep, hydromechanical behavior, earlywood, grid method, latewood, recovery.

\section{Introduction}

Wood is a material which perfectly suits the requirements of sustainable development. However, the variability of properties within this heterogeneous material and its highly complex behavior constitute a real scientific problem. Indeed, under constant mechanical stress, wood strain increases over time. After unloading, a delayed recovery phase is observed (Dubois (1997), Randriambololona (2003), Merakeb (2006), Moutou Pitti (2008), Saifouni (2014)). With a constant moisture content $(M C)$, the level of creep strain increases when the applied stress is high. Furthermore, with constant stress and under two different humidity conditions, the creep level is more pronounced with the higher humidity level (Pittet (1996)). This shows the softening power of humidity on wood. Indeed, wood is very sensitive to $M C$ changes below the fiber saturation point 
(FSP). In the literature some rheological models are proposed to represent the viscoelastic behavior of wood (Moutee (2006)).

Several studies have also focused on the influence of $M C$ on the behavior of wood under mechanical stress (Armstrong et al. (1960), Armstrong \& Christensen (1961), Armstrong \& Kingston (1962)). In addition, Gril (1988) highlighted the effect of drying or moistening on wood deformation under mechanical load. Indeed, it was found that under constant mechanical stress and below the FSP, an increase or a decrease in $M C$ caused an increase in the total strain level. This phenomenon, named mechanosorption, is a consequence of the coupling between humidity and mechanical stress (Hunt (1989), Pittet (1996), Randriambololona (2003), Moutee (2006), Saifouni et al. (2016)). Armstrong \& Kingston (1962) and Hunt (1984) performed experiments on specimens with relatively large dimensions. This can make the obtained results difficult to interpret, because the mechanosorptive strain can be embedded in the total strain. Other ef- fects, such as dimensional variations, must also be taken into account. Some authors, such as Pittet (1996) and Saifouni (2014) performed "pure" mechanosorptive tests on specimens with small dimensions to neglect the effects of $M C$ gradients. However, such dimensions make the compression tests tricky to perform because of potential buckling.

The above-cited literature studies also do not take into account the local gradients of properties such as the presence of earlywood $(E W)$ and latewood $(L W)$ for the characterization of the thermohydro-mechanical behavior of wood. Local gradients should be considered as soon as tests are performed on very thin specimens, as is generally the case for "pure" mechanosorptive tests. Indeed, the thinner the specimen, the closer its behavior is to local properties instead of global ones. It is therefore necessary to carry out tests to highlight the heterogeneity of the wood response due to the presence of local gradients.

The use of full-field measurement techniques provides a heterogeneous response for a material with property gradients. Various contactless imaging techniques have already been used to characterize the behavior of wood. Some authors, such as Pop et al. (2011), Méité et al. (2013), Xavier et al. (2014), Silva et al. (2014), used digital image correlation (DIC) to characterize wood cracking parameters. Recently, Gauvin et al. (2014) performed longitudinal adsorption tests on populus specimens with a thickness of between 6 and $10 \mathrm{~mm}$ using DIC. Neutron imaging $(N I)$ and X-ray imaging have also been used for wood characterization. Sanabria et al. (2015) studied wood under $M C$ equilibrium by using the NI technique. Marčok et al. (1996), Sahlberg et al. (1997), Cave (1997), Freyburger et al. (2009) and Tanaka et al. (2009) investigated wood material using X-ray imaging. Another contactless and white light technique used for full-field measurements is the grid method. Recently, this technique has been efficiently used by Dang et al. $(2014,2016,2017)$ to investigate the variability of the hydric properties of wood at the ring scale, especially in $L W$ and in $E W$. In these last works the effects of THM is neglected. The grid method is known to provide 
a good compromise between measurement resolution, which can be defined as the reliable information that emerges from the noise floor, and spatial resolution, which reflects the ability of a technique to distinguish fine details in a strain map. It is thus a technique which is suitable for characterizing gradient properties, and it was therefore used in the present study Grediac et al. (2016).

The present work aims to investigate wood material behavior at the ring scale during free drying under creep/recovery cycles using the grid method. In the first section, the materials and methods are presented. Secondly, the experimental results are presented and discussed. Finally, conclusions and perspectives close the paper.

\section{Materials and methods}

\subsection{Materials}

The tested specimens were obtained from the same white fir tree of the Massif Central (Abies alba Mill), France. Figure 1 shows the zones from which the specimens came. The front face under investigation and the side faces of each of these specimens are shown in Figure 2. Significant differences in the size and inclination of the annual growth rings are observed in the $(R, T)$ and $(R$, L) planes. This undoubtedly impacts the response of each specimen in terms of deformation. The dimensions of the specimens are shown in Figure 2. The (L, R) faces shown in Figure 2 were investigated.

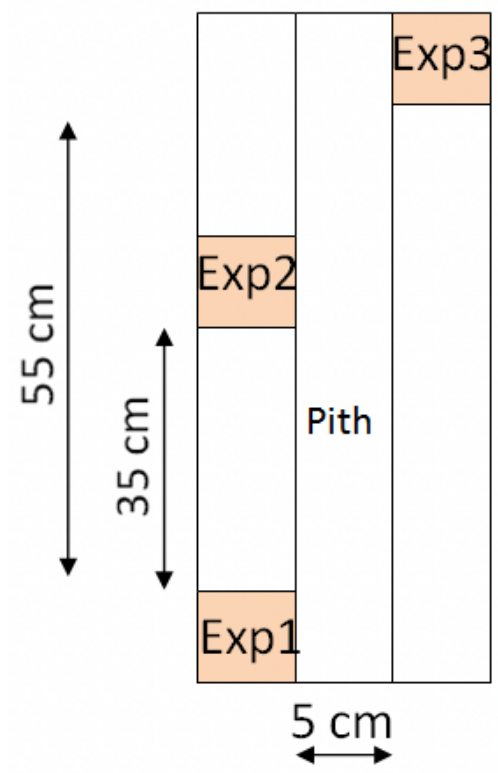

Figure 1: Sampling zones 
A crossed grid with a pitch equal to $200 \mu \mathrm{m}\left(5\right.$ lines $\left.\mathrm{mm}^{-1}\right)$ was transferred onto the front face of each specimen using the procedure given in Piro \& Grédiac (2004) (see Figure 3 for an example of a grid). The other sides were free to interact with their environment. Their initial $M C$ was $12 \%$ on average, using the double weighing method. The glue used to support the transferred grid is hydrophobic. Its mass was assumed to be constant. $M C$ was determined from the masses in which the presence of the grid was taken into account. Each specimen was immersed in water for a period of less than 24 hours, after transferring the grid and after weighing its mass before immersion. After immersion, the specimen was wiped to remove any water film on the surface, and weighed again to determine its $M C$. This latter was greater than the FSP (supposed to be equal to $30 \%$ in the present study). Each of the specimens was left in a room under controlled humidity and temperature conditions in order to undergo free natural drying. As the natural drying took place, the specimen was regularly weighed to check whether its $M C$ was close to $30 \%$. When the intrinsic $M C$ was found to be sufficiently close to this value, the mechanical load was applied. Table 1 presents the masses before and after transfer of the grid onto each of the specimens. It also presents the $M C$ immediately after immersion and before applying mechanical loading to each specimen. During each experiment, the temperature (Temp) and relative humidity $(R H)$ of the room were regularly registered by a remotely-controlled thermohygrometer. Table 1 shows the average temperature and relative humidity values as well as their standard deviation (STD) during each experiment. As can be seen in this table, the hygrothermal conditions of the room were not constant for a given experiment. These conditions also changed from one experiment to another. Fluctuations in the relative humidity were more pronounced than those of the temperature. Hygrothermal fluctuations were more significant during the third experiment. The consequence is that comparing the experimental results of these three experiments will be difficult.

Table 1: Temperature and moisture conditions

$\begin{array}{lrrr}\text { Designations } & \text { Experiment 1 } & \text { Experiment 2 } & \text { Experiment 3 } \\ \text { Mass }_{\text {withoutgrid }}(g) & 16.7 & 18.00 & 16.87 \\ \text { Mass }_{\text {withyrid }}(g) & 17.73 & 19.02 & 17.66 \\ \mathrm{~W}_{\text {afterimmersion }}(\%) & 45.60 & 86.74 & 57.42 \\ \mathrm{~W}_{\text {beforeloading }}(\%) & 36.62 & 36.28 & 32.69 \\ \mathrm{RH}_{\text {mean }}(\%) & 48.33 & 36.74 & 34.81 \\ \operatorname{STD}_{R H}(\%) & 2.29 & 3.07 & 3.38 \\ \operatorname{Temp}_{\text {mean }}\left({ }^{\circ} \mathrm{C}\right) & 21.85 & 18.37 & 22.01 \\ \operatorname{STD}_{\text {Temp }}\left({ }^{\circ} \mathrm{C}\right) & 0.32 & 0.48 & 1.21\end{array}$




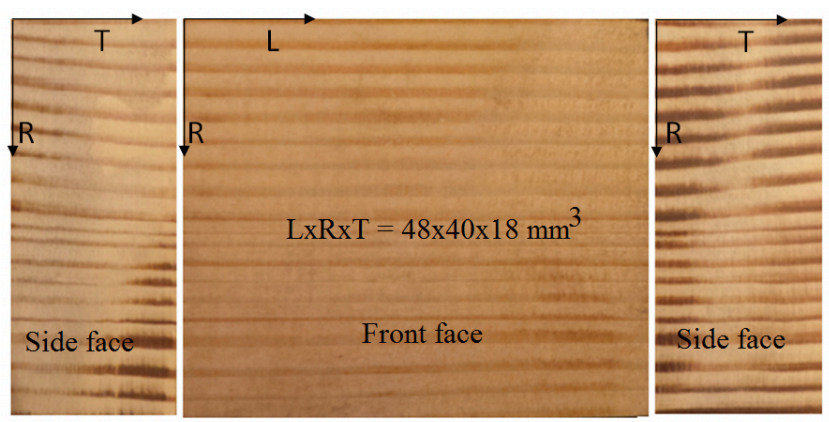

a)-Experiment 1

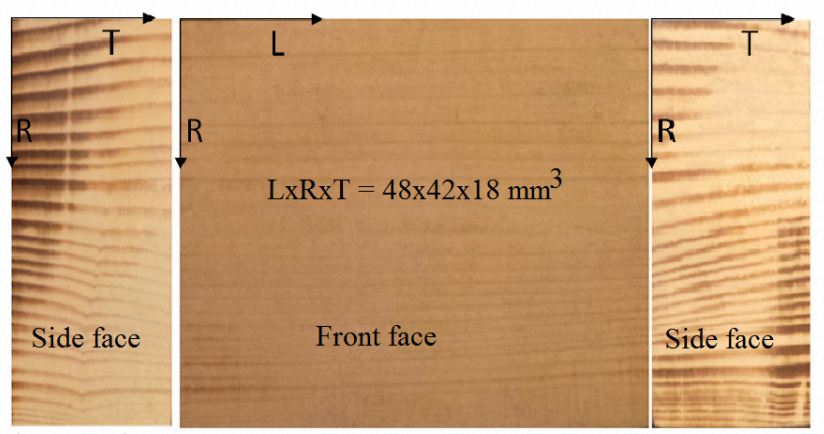

b)-Experiment 2
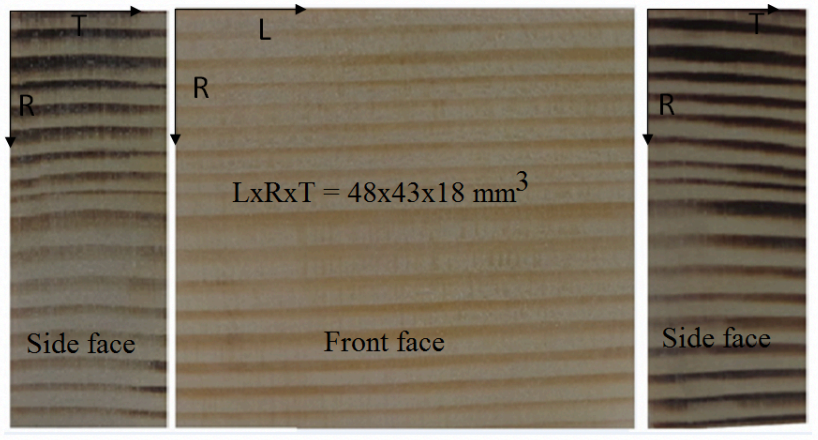

c)-Experiment 3

Figure 2: Front faces and sides of the specimens used in the experiments

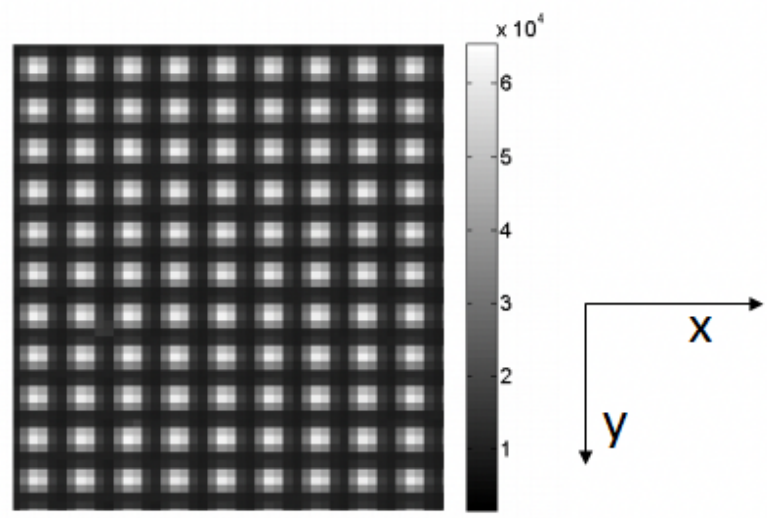

Figure 3: Close-up of a grid; the pitch is $0.2 \mathrm{~mm}$ 


\subsection{Testing conditions}

\subsubsection{Experimental setup}

The experimental device consisted of a 12-bit 1040×1376 Sensicam Camware software. This camera is equipped with a cooled charge-coupled device (CCD) sensor. The camera was positioned and calibrated to obtain suitable experimental settings. For instance, the front face of the specimen has to be aligned parallel to the plane of the CCD sensor by adjusting system settings. The distance between the specimen and the camera must also be adjusted in such a way that approximately 5 pixels are used to encode one grid pitch. A KL 2500 LCD (liquid crystal display) cold light source feeding three flexible and movable light guides was used to illuminate the face under investigation, leading to the nearly uniform lighting of the camera with its accompanying grid. A 50-kN Zwick testing machine was used to apply the compression load. Each of the tested specimens had to be removed to be weighed in order to estimate the global $M C$, or to be carefully wrapped in an isothermal bag during the nights, because the duration of one test was more than one day. The efficiency of this system was validated using another specimen of Abies alba Mill. Indeed, for a total of 55 hours, the total mass loss was $5.23 \%$, corresponding to a water loss rate of 9.5E-02 $\%$ /hour; thus the mass loss was less than $2 \%$ over one night. Each specimen was weighed at the beginning and at the end of every creep step. The same process was used for the recovery phases.

To ensure the correct repositioning of each specimen during the creep and recovery cycles, a tracking system with respect to the location of the camera was developed. This tracking system consisted of two metallic rings glued onto the specimen holder at a tangent to the specimen They were positioned in front of the specimen (see Figure 4) and enabled the distance between specimen and camera to remain constant. A horizontal line was drawn on the specimen holder with respect to the axis of symmetry of the tested specimen (plane $(R, T)$ ). This tracking line enabled us to ensure the correct positioning of the tested specimen according to the axis of symmetry of the camera. To complete this system, a vertical line was drawn on the opposite side of each tested specimen with respect to its geometric axis of symmetry (plane $(\mathrm{L}, \mathrm{R})$ ). It was thus possible to ensure the correct positioning of each tested specimen whenever necessary. To ensure the uniform distribution of the load applied to the specimen, a small strip of elastomer was placed on the latter in order to absorb possible surface irregularities. Grid images were recorded at different times during each experiment. Strain maps were then deduced from the grid images using in-house dedicated software.

\subsubsection{Loading/unloading cycles}

The loading/unloading process for Experiments 1, 2 and 3 is presented in Figure 5-a, -b and -c respectively. For each experiment, the loading level $(1.5 \mathrm{kN})$ and the duration of the recovery phase 
( 2 hours) were the same. The applied compressive load was radial. However, the loading time differed from one experiment to another in order to highlight its effects. As already mentioned, a sufficiently long loading duration is necessary for creep and mechanosorptive effects to occur, but it must be short enough to avoid significant weight loss. Indeed, during each experiment the mass of the specimen was only known at the beginning and at the end of each loading phase.

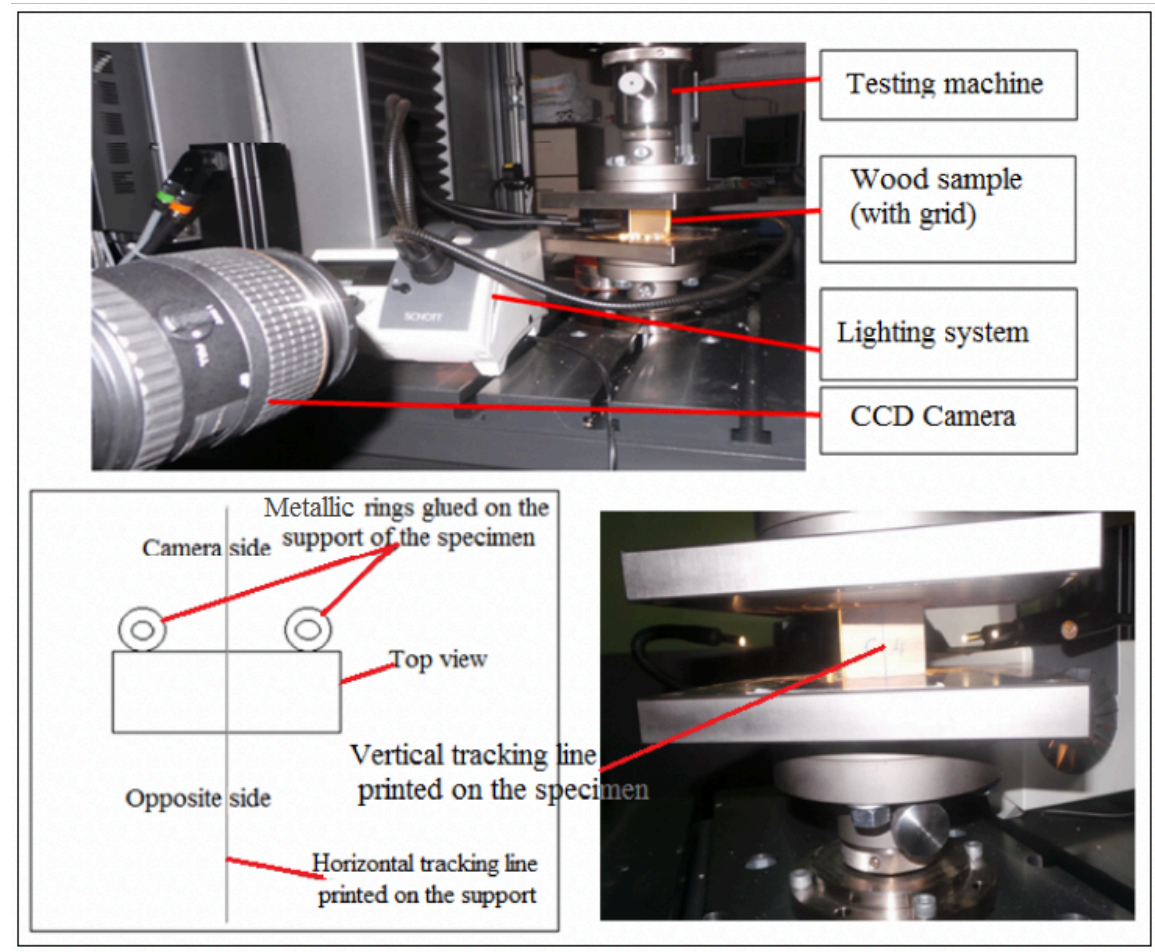

Figure 4: Experimental setup

\subsubsection{Image acquisition}

To minimize the effect of noise during image acquisition, the Camware software was set to averaging mode. However, the number of frames to be averaged, denoted $N_{i m}$ in the following, must be chosen to avoid notable geometric changes in each tested specimen during the acquisition of the $N_{i m}$ single frames. About one second was sufficient to average 8 frames in order to avoid any notable change in each studied specimen. An automation macro was used to monitor Camware in averaging mode. The duration between two averaged images for each experiment is given below:

- one averaged image every 15 seconds during the creep phases of Experiment 1,

- one averaged image every 10 seconds during the creep phases of Experiment 2,

- one averaged image every 15 seconds during the creep phases of Experiment 3,

- one averaged image every 5 minutes during the recovery phases of Experiment 3.

The basics of the grid method used to deduce strain fields from images are presented in subsection 1.3 . 

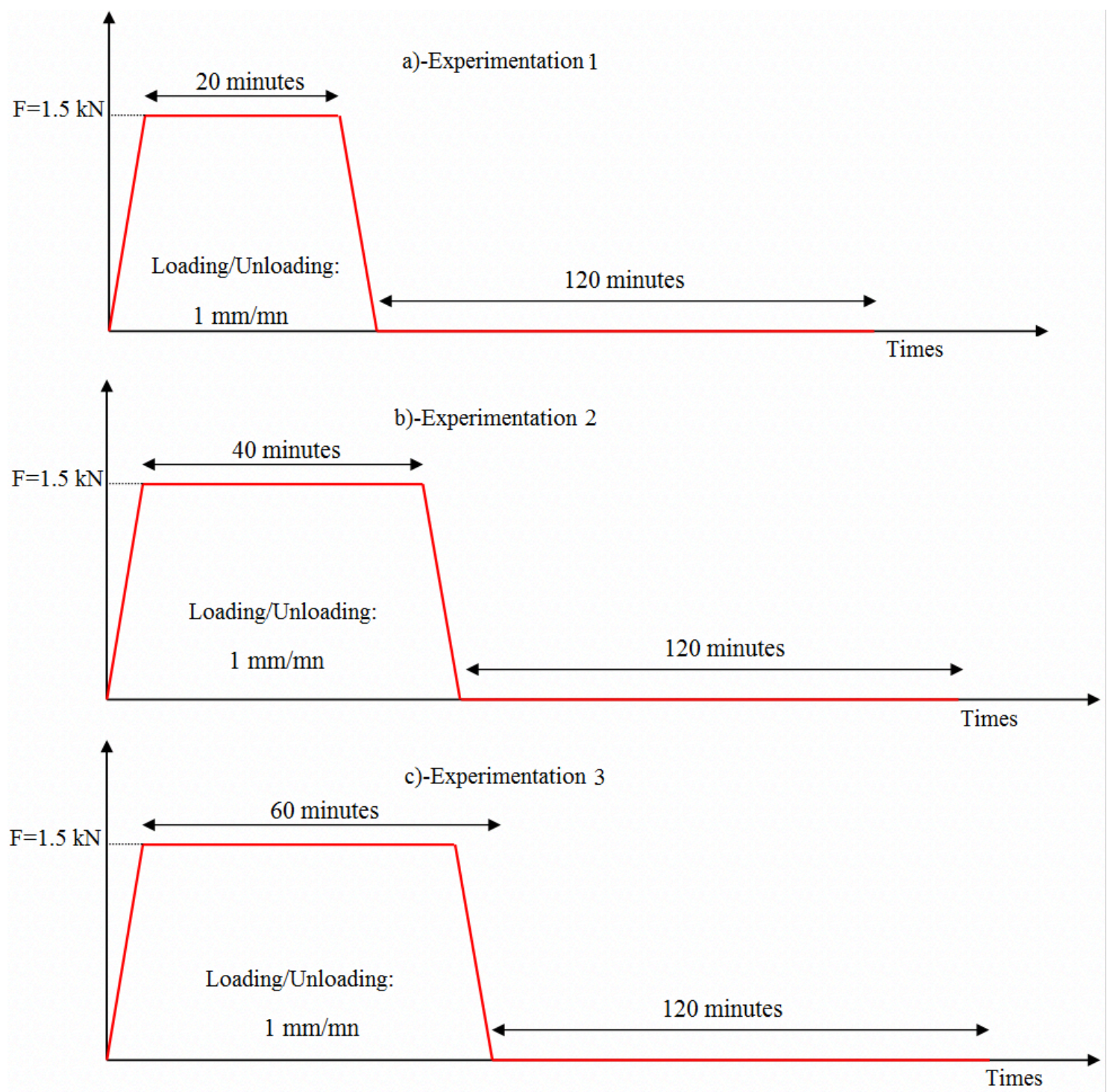

Figure 5: Loading/unloading cycles

\subsection{A brief reminder of the grid method}

The grid method is a contactless and white-light measurement technique which enables in-plane displacement and strain fields to be calculated. It is well suited here thanks to its good compromise between resolution and spatial resolution Grediac et al. (2016). We consider a bidirectional grid (see Figure 3) transferred onto the surface of the studied specimen, for instance using the technique proposed in Piro \& Grédiac (2004). The x- and y-axes are here parallel to the lines of the grid. The light intensity $S(x, y)$, at each pixel of coordinates $(x, y)$ can be modeled as follows:

$$
S(x, y)=\frac{A}{2}\left[2+\gamma \cdot f r g n\left(2 \pi f x+\Phi_{x}+\gamma \cdot f r g n\left(2 \pi f y+\Phi_{y}\right]\right.\right.
$$


where $\gamma$ is the contrast, $A$ the amplitude, $f r g n$ a $2 \pi$ periodic function, $f$ the frequency of the carrier defined by the inverse of its pitch $p$, and $\Phi_{x}$ and $\Phi_{y}$ are the phases along the $x-$ and $y-$ axes, respectively Badulescu et al. (2009). $\Phi_{x}$ (respectively $\Phi_{y}$ ) and the in-plane displacement $u_{x}$ (respectively $u_{y}$ ) are linked through Equation 2:

$$
\left\{\begin{array}{l}
u_{x}=\frac{-p}{2 \pi} \cdot \Delta \Phi_{x} \\
u_{y}=\frac{-p}{2 \pi} \cdot \Delta \Phi_{y} S
\end{array}\right.
$$

$\Delta \Phi_{x}$ and $\Delta \Phi_{y}$ are the phase changes between the final and initial images using the Windowed Fourier Transform (WFT) along the $x$ - and $y$ - axes, respectively, as specified in Badulescu et al. (2009). Assuming a small deformation hypothesis, the strain components are related to the displacements as follows:

$$
\left\{\begin{array}{c}
\varepsilon_{x}=\frac{\partial u_{x}}{\partial x} \\
\varepsilon_{y}=\frac{\partial u_{y}}{\partial y} \\
2 \varepsilon_{x y}=\frac{\partial u_{x}}{\partial y}+\frac{\partial u_{y}}{\partial x}
\end{array}\right.
$$

From Equations 2 and 3, the strains can be rewritten as indicated in Equation 4.

$$
\left\{\begin{array}{c}
\varepsilon_{x}=\frac{-p}{2 \pi} \Delta\left(\frac{\partial \Phi_{x}}{\partial x}\right) \\
\varepsilon_{y}=\frac{-p}{2 \pi} \Delta\left(\frac{\partial \Phi_{y}}{\partial y}\right) \\
2 \varepsilon_{x y}=\frac{-p}{2 \pi}\left[\Delta\left(\frac{\partial \Phi_{x}}{\partial y}\right)+\Delta\left(\frac{\partial \Phi_{y}}{\partial x}\right)\right]
\end{array}\right.
$$

For a complete review on the grid method, see Badulescu et al. (2009) and Grediac et al. (2016). The experimental results obtained are presented and discussed in the following section.

\section{Experimental results and discussion}

\subsection{Experiment 1}

Dimensions are given in pixels in the strain maps presented here, one pixel representing $40 \mathrm{mi}$ crons for each specimen. Sixteen creep/recovery cycles were performed on the tested specimen. Images were acquired only during the creep phases. Figure 6 shows typical radial strain maps corresponding to the creep phase of the first cycle. Figure 7 presents typical radial strain maps corresponding to the creep phase of the last cycle. As can be seen from these maps, the level of negative strain in EW increases progressively during the loading phase of the test. This finding is in agreement with the results that are expected during compressive creep tests. However, a positive 
strain occurs at the beginning of each cycle, particularly in $L W$, which is counter- intuitive. Indeed, after immersion small bumps, corresponding to $L W$, were observed; under compression these effects became more pronounced with the appearance of local tension. This could explain the presence of these positive strains throughout the experiment. Note that the average strain always remains negative, which is quite logical. When comparing the strain levels reached during the first and last creep phases for the same loading, it appears that these negative strains are more pronounced in the last phase. This is quite logical because the strain maps are determined with respect to an image taken just before starting the first cycle. Indeed, these strain maps include all the hydromechanical history of the specimen from the first cycle. This history includes the strain related to shrinkage, elastic deformations and viscoelasticity as well as the effects of mechanosorption. During the creep phase of the first cycle, the $M C$ drops from $32.62 \%$ to 29.78 $\%$, which corresponds to a mass loss of $2.82 \%$. Regarding the creep phase of the last cycle, the $M C$ decreases from $7.17 \%$ to $6.95 \%$, which corresponds to a very low mass loss of $0.22 \%$ due to the end of natural drying process. Between the first and the last cycles, the specimen undergoes a mass loss of $25.45 \%$.
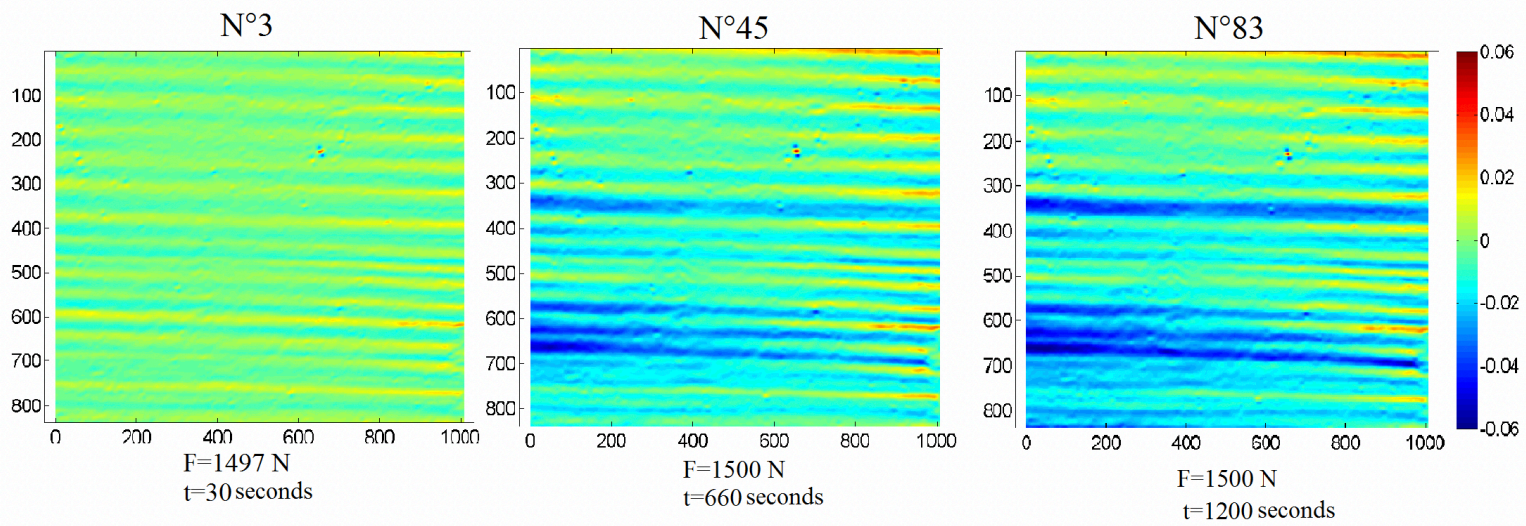

Figure 6: Radial strain maps during the creep phase of the first cycle $\left(S_{I}\right)$
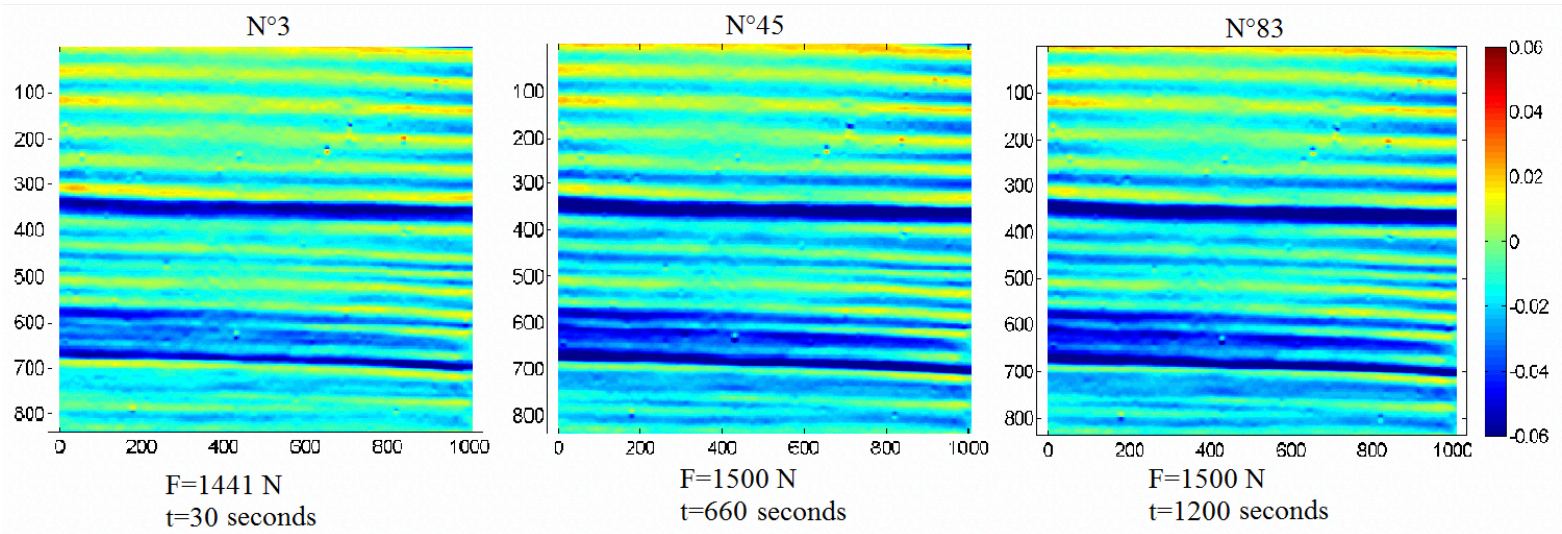

Figure 7: Radial strain maps during the creep phase of the last cycle $\left(S_{l}\right)$ 


\subsection{Experiment 2}

The radial strain maps obtained during the second experiment are presented in Figures 8 and 8 . Eight creep/recovery cycles were performed. As in Experiment 1, image acquisition was performed during the creep phase only. The cumulative duration of all the creep phases was the same for Experiments 1 and 2, the only difference being the duration of the creep phase (40 minutes instead of 20 for Experiment 2) and the number of cycles ( 8 instead of 16 for Experiment 2). These differences are related to the experimental conditions and the objective of finding an appropriate creep period enabling us to observe the desired phenomena (viscoelastic and mechanosorptive effects). The duration of the recovery phase in Experiments 1 and 2 was the same for each cycle; thus if the two specimens tested were materially the same, the unrecovered strain level would be more pronounced for Experiment 2. Figure 8 shows typical radial strain maps corresponding to the creep phase of the first cycle. Figure 9 presents some radial strain maps corresponding to the creep phase of the last cycle. The strain maps in Figure 8 show that the creep response of the specimen tested in Experiment 2 is less pronounced in the first cycle compared to that of the specimen tested in Experiment 1. In addition, during this second experiment, we can notice in Figure 8 that the level of positive strain is lower compared to that observed in the first cycle of Experiment 1 (Figure 6). Note that even if the tested specimens in Experiments 1 and 2 are from the same tree and the same board, they were cut at a distance of $35 \mathrm{~cm}$ with respect to each other. This may explain the differences observed in their response in terms of deformation. Indeed, the spatial variability of properties depending on the sampling area along the trunk can be suspected as being the source of these significant differences. However, during the creep phase of the last cycle of Experiment 2 (see Figure 9), the deformation of the specimen is similar to that obtained during the creep phase of the last cycle of Experiment 1 (see Figure 7). Indeed, Figure 9 shows a negative strain level which is very pronounced in $E W$, as is the case for Experiment 1 . The increase in strain level compared to the first cycle is due to the hydromechanical load history.
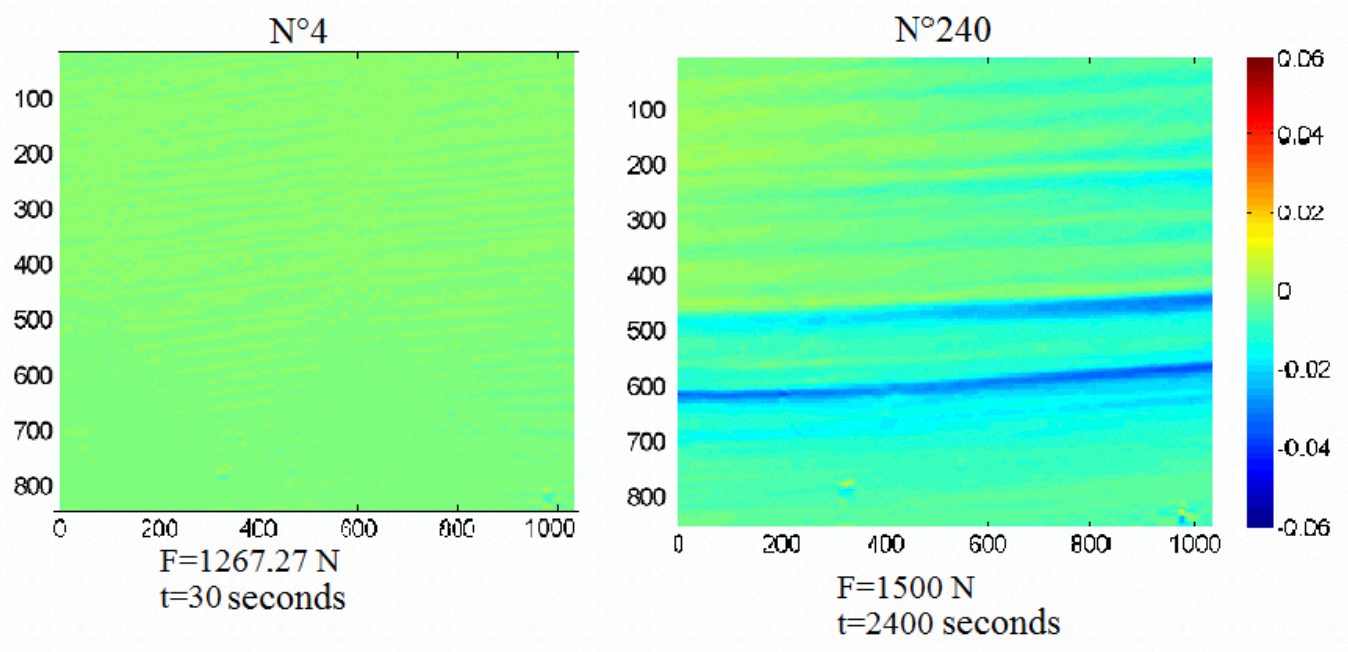
Figure 8: Radial strain maps during the creep phase of the first cycle $\left(S_{2}\right)$
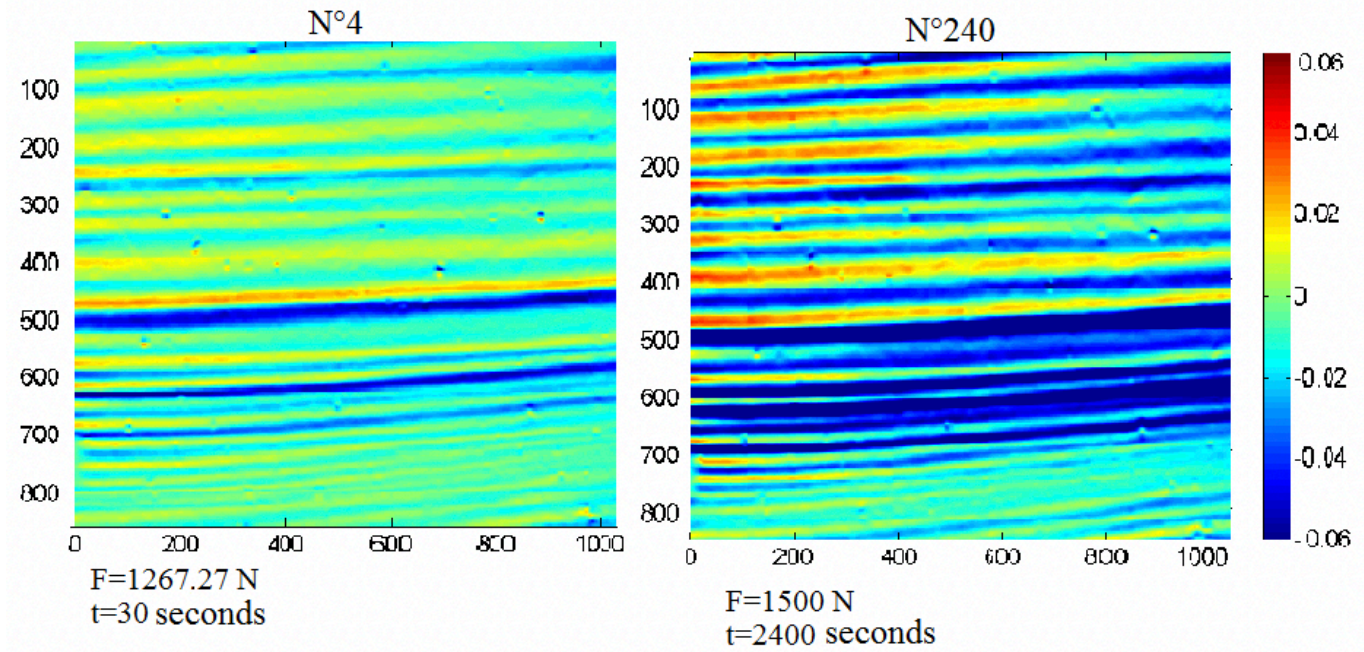

Figure 9: Radial strain maps during the creep phase of the last cycle $\left(S_{2}\right)$

This strain includes deformations related to shrinkage, elastic deformations, viscoelasticity and mechanosorptive effects. Note also that the level of positive strain is significant compared to the first cycle, certainly because of shape effects in $L W$ amplified by the hydromechanical history. During the first cycle of the creep phase, the $M C$ drops from $36.4 \%$ to $34.8 \%$, corresponding to a mass loss of $1.56 \%$, which is lower than during the phase creep for Experiment 1. Regarding the creep phase of the last cycle, the $M C$ decreases from $17.7 \%$ to $17 \%$, which corresponds to a mass loss low of $0.7 \%$. Between the beginning of the first cycle and the last cycle the total mass loss of the specimen is $18.96 \%$.

Heterogeneous responses from Experiments 1 and 2 confirm the ability of full-field measurement techniques, in particular the grid method, to reveal singularities related to local properties of the material during creep. The results obtained show the presence of alternate positive and negative values for the strain. This makes it difficult, if not impossible, to threshold the strain maps in order to extract the negative strains, especially in LW. To better understand the origin of these positive strain values, strain maps corresponding to a reference image taken before immersion, and a current image taken after immersion and before the compression test, are studied.

\subsection{Experiment 3}

Figure 10 presents the different phases of Experiment 3. This figure also shows the reference images that can be used to obtain strain maps with or without the hydromechanical history. When strain maps are obtained from the reference image Imref 0 , the past hydromechanical history of the specimen is taken into account, which is not the case if the reference image is Imref $k ; k=1,2,3,4$ where $k$ is the number of the cycle. The results obtained with these various reference images are 
presented here.

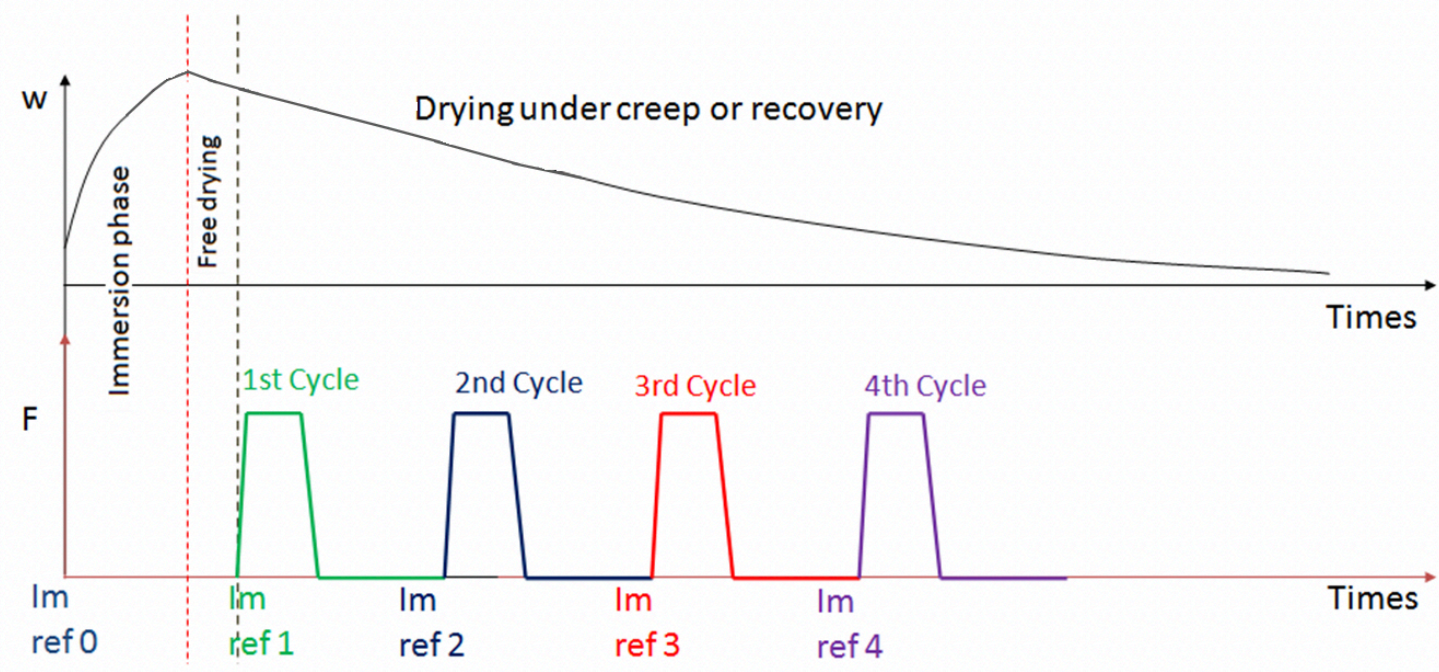

Figure 10: Phases of Experiment 3

Immersion and free drying phases: as previously shown in Table 1, the specimen was immersed before testing. Then it underwent natural drying to a $M C$ level slightly greater than the FSP. During the immersion phase, its $M C$ increased from $12 \%$ to $57.4 \%$, and then decreased to $32.7 \%$ at the end of the free drying phase. Image acquisition was performed during the free drying phase, which lasted 10 hours. Figure 11 presents the strain maps at the beginning and at the end of the free drying process. The presence of positive strains is due to the water immersion. The strain in $L W$ is more pronounced than in $E W$; this finding is in agreement with the conclusions presented in Watanabe et al. (1998), Dang et al. (2014, 2016) and Dang et al. (2017). The increase in positive strain when the specimen is subjected to free natural drying can be explained by the fact that the studied face is not directly exposed to the environment. Indeed, since the five other faces of the specimen are in direct contact with ambient air, they will dry quickly, which induces an increase in positive strain on the side bearing the grid. Although the duration of the natural drying process is relatively long (10 hours), the drying kinetics depend only on the hygrothermal surrounding conditions and the surface exchanges. With low and relatively constant $\mathrm{T}$ and $\mathrm{RH}$, the shrinkage may progress more slowly. The level of negative strain $\left(1^{-04}\right)$ illustrates the low drying rate affecting the investigated face. This behavior during the free drying phase enables us to understand the presence of the positive strains observed in the radial strain maps during Experiments 1 and 2. Now the radial strain maps of Experiment 3 during both creep and recovery phases will be presented. 

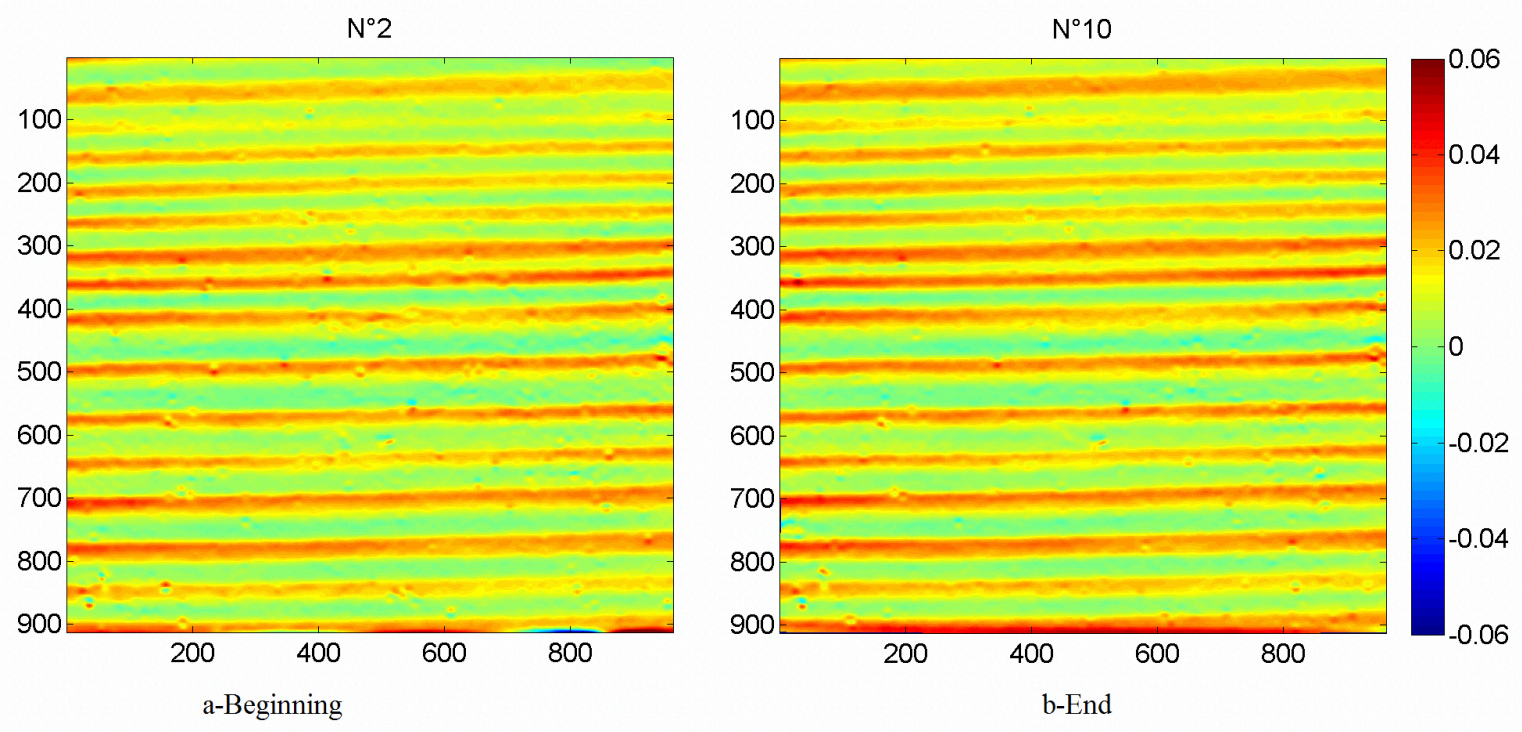

Figure 11: Radial strain maps during the free drying phase $\left(S_{3}\right)$

Radial strain maps : some radial strain maps corresponding to creep of the first cycle are presented in Figure 12. These strain maps are obtained from images acquired under mechanical loading, using Imref 0 as a reference image (see Figure 10). Hence these strain maps take into account the hydromechanical history of the tested specimen. During this creep phase, the $M C$ drops from 32.7 $\% 30.1 \%$. As can be seen, the level of negative strain increases during the test. Nevertheless, positive strain components are still present in some zones of the specimen, even if they are reduced or absent in others. The positive strains mainly affect $L W$. $E W$ evinces a negative strain level which is higher than that of $L W$ because of its lower stiffness (Peck (1933), Cramer et al. (2005), Pereira et al. (2013)). The top right zone of the specimen exhibits higher strain values. This feature can potentially have several causes, for instance the heterogeneity of the material or the experimental boundary conditions.

Figure 13 shows typical strain maps obtained during the recovery phase of the first cycle of Experiment 3. These strain maps are obtained from images taken during drying and without mechanical loading. Here, the reference image is Imref 0 (see Figure 10). They therefore reflect the whole hydromechanical history of the tested specimen. During this recovery phase, $M C$ decreases from $30.1 \%$ to $25.7 \%$. 

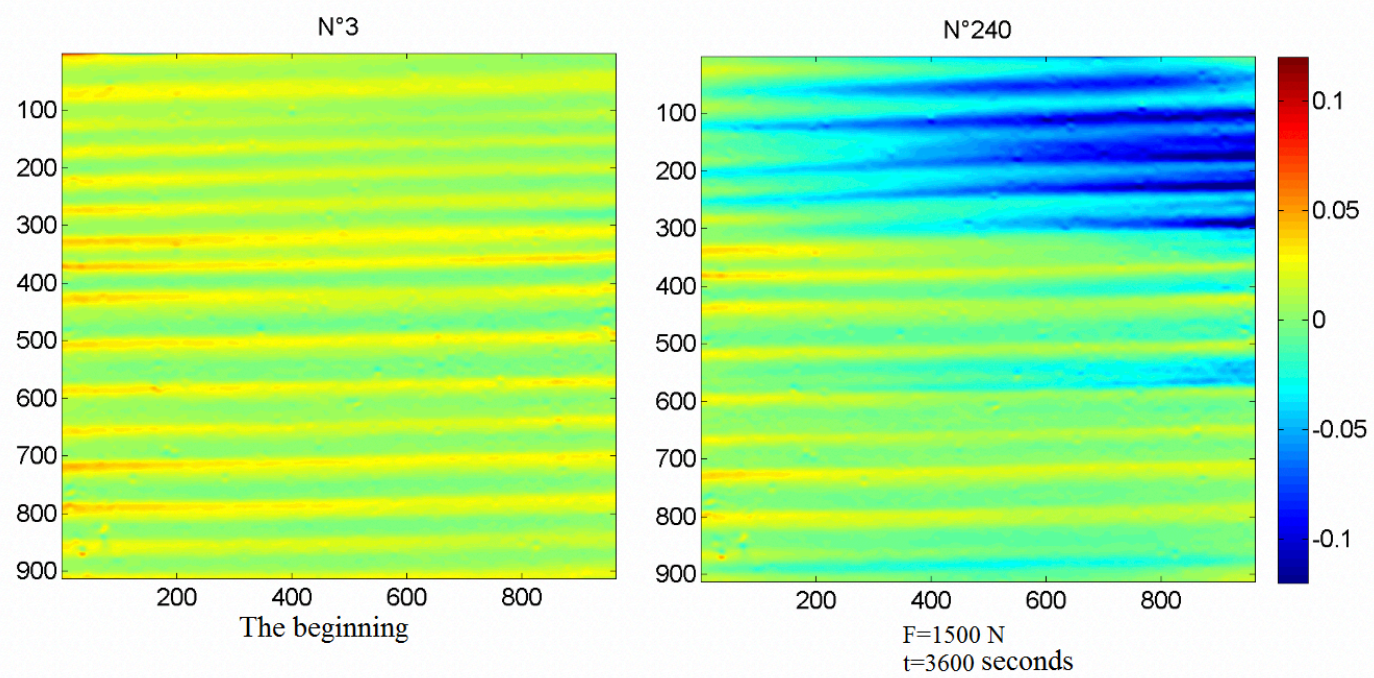

Figure 12: Radial strain maps including hydromechanical history during the creep phase of cycle 1

The difference between the strain level in the last strain map of the creep phase of the first cycle (map $\mathrm{N}^{\circ} 240$ Figure 12) and the first strain map during the recovery phase (map $\mathrm{N}^{\circ} 2$ in Figure 13), is noticeable. This difference is certainly due to the elastic return of the material. Indeed, between the end of the creep phase and the beginning of recovery phase monitoring, the specimen is removed for weighing. During this time interval, no image is taken, so a small portion of the information during the recovery phase is lost. The times at which images were acquired during recovery and when this recovery phase really started are different. Moreover, it can be noted from Figure 13 that the negative strain level is lower than in Figure 12. At the same time, the level of positive strain increases. The deformation state of the studied face at the end of the recovery phase of the first cycle (see map $\mathrm{N}^{\circ} 25$ Figure 13) is similar to map $\mathrm{N}^{\circ} 3$ in Figure 12 (earlier mechanical loading). It can be concluded that during the first creep / recovery cycle, the strain is almost completely recovered.

Figure 14 shows the same strain maps as those shown in Figure 12, but without considering the whole hydromechanical history, since the maps are obtained by considering Imref 1 as a reference image (see Figure 10). When comparing the strains maps in these two figures, the first observation is that for the map $\mathrm{N}^{\circ} 3$ presented in Figure 14, the strain is almost null everywhere. However, in the other maps of this figure, we note the presence of positive deformations. Their amplitude is very small compared to that obtained when considering the whole hydromechanical history. These positive strains therefore appear only during the creep phase of cycle 1 in this case. In addition, map $\mathrm{N}^{\circ} 240$ in Figure 14 exhibits a higher level of negative strain than when including hydromechanical history (Figure 12, map $\mathrm{N}^{\circ} 240$ ). This means that when including the past hydromechanical history of the specimen, the amplitude of the negative strain decreases. Figure 15 shows radial strain maps during the creep phase of the second cycle. They take into account the 
hydromechanical history of the specimen (Imref 0 is the reference image). During this creep phase, the $M C$ drops from $25.7 \%$ to $23.7 \%$. The strain distribution profile is similar to that obtained during the creep phase of cycle 1 . Our observations are the same as in the creep phase of the first cycle. Indeed, there is an increase in the negative strain level in both $E W$ and $L W$, and the strain in $L W$ remains positive in some zones, mainly for the same reasons as those mentioned above for cycle 1.
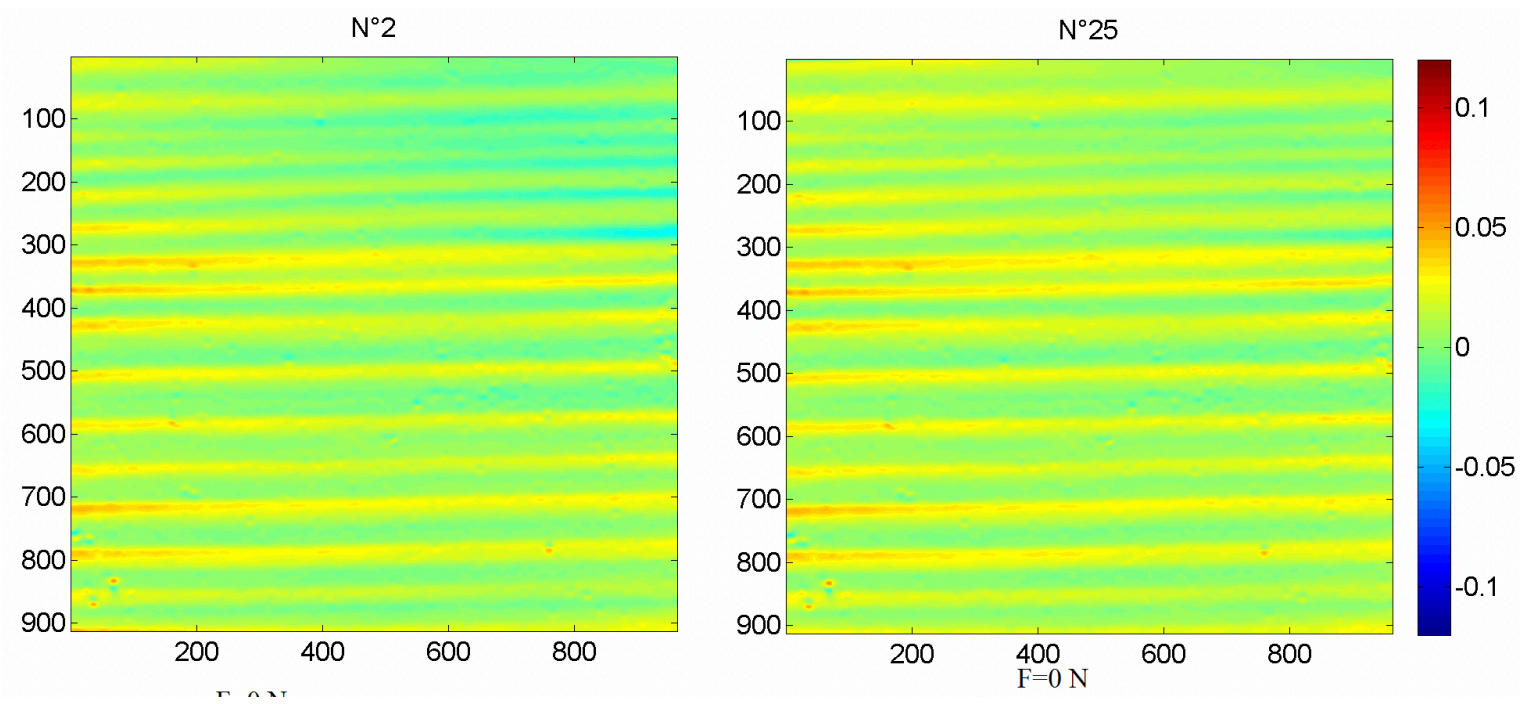

Figure 13: Radial strain maps including hydromechanical history during the recovery phase of cycle 1

Note that the level of negative strain during this creep phase is slightly higher than that of the first cycle. This increase may be related to changes in intrinsic $M C$ that may impact the mechanical characteristics. Indeed, the level and the duration of the loading are the same as in cycle 1, so any increase in the negative strain level can be related to $M C$ variations and their coupling with the mechanical loading. Figure 16 presents the strain maps of the creep phase of the second cycle without the prior hydromechanical history of the experiment in terms of deformation. The reference image is now Imref 2 (see Figure 10). As in the case of cycle 1, we note that there is no positive strain at the beginning of cycle 2 (see map $\mathrm{N}^{\circ} 2$ in Figure 16). Map $\mathrm{N}^{\circ} 240$ in Figure 16 shows an increase in the negative strain level compared to maps $\mathrm{N}^{\circ} 240$ in Figure 15. Therefore, as in the case of the creep cycle in phase 1, taking into account the hydromechanical history in terms of strain leads to a decrease in the negative strain level. However, there is also a small positive strain, as in the creep phase of the first cycle and certainly for the same reason.

Now let us turn to the recovery phase of cycle 2 in Figure 16. The strain maps presented in this figure are obtained using Imref 0 as a reference image in order to take into account the whole hydromechanical history. A notable difference can be observed between map $\mathrm{N}^{\circ} 2$ in Figure 16 and the last map of the creep phase of cycle 2 in terms of strain (map $\mathrm{N}^{\circ} 240$ in Figure 15). This is due to the same reason as that evoked for the recovery phase of cycle 1, i.e. part of the strain recovery 
occurs before the beginning of imaging. However, contrary to the end of the recovery in cycle 1, the last strain map ( $\mathrm{N}^{\circ} 25$ Figure 16) indicates that the negative strain is not fully recovered. Since the duration of the recovery phase is the same as in cycle 1, a possible reason is a higher strain level in the creep phase of cycle 2 . We can deduce that, in addition to deformations related to the shrinkage, the elastic behavior, viscoelastic and mechanosorptive effects, and deformations during the creep phase from cycle 3 include unrecovered strains.

It should be noted that the behavior exhibited by the specimen tested in Experiment 3 is different in terms of deformation from the two previous experiments (1 and 2). Despite this remark, the same phenomena related to the appearance of positive and negative strains at the ring scale were observed in the three experiments. We already mentioned that it was difficult to threshold the strain maps obtained in experiments 1 and 2. However, we can threshold the strain maps from experiment 3 to further investigate the creep/recovery behavior under drying at the ring scale.

Investigation of creep/recovery at the ring scale: a thresholding procedure is performed to study strain variation versus time in $E W$ and $L W$. The objective is to build masks which allow us to extract strains from pixels belonging to $E W$ and to $L W$. A zone of interest is first defined where significant negative strains in $E W$ and $L W$ are obtained simultaneously. Thresholding is then performed in this zone of interest from the last strain map of the creep phase. To obtain the masks from the thresholding procedure, the minimum and maximum values of the strain in $E W$ and in $L W$ must be defined. An example of a zone of interest is shown in Figure 18. Equation 5 is applied to the zone of interest to generate the masks for $E W$ and $L W$. For cycle 1, the thresholding bounds are: $\varepsilon_{E W_{\min }}=-0.15, \varepsilon_{E W_{\max }}=-0.08, \varepsilon_{L W_{\min }}=-0.045$ and $\varepsilon_{L W_{\max }}=0$.

$$
\varepsilon_{E W_{\text {min }}}<\varepsilon_{E W}<\varepsilon_{E W_{\max }} \text { and } \varepsilon_{L W_{\text {min }}}<\varepsilon_{L W}<\varepsilon_{L W_{\max }}
$$
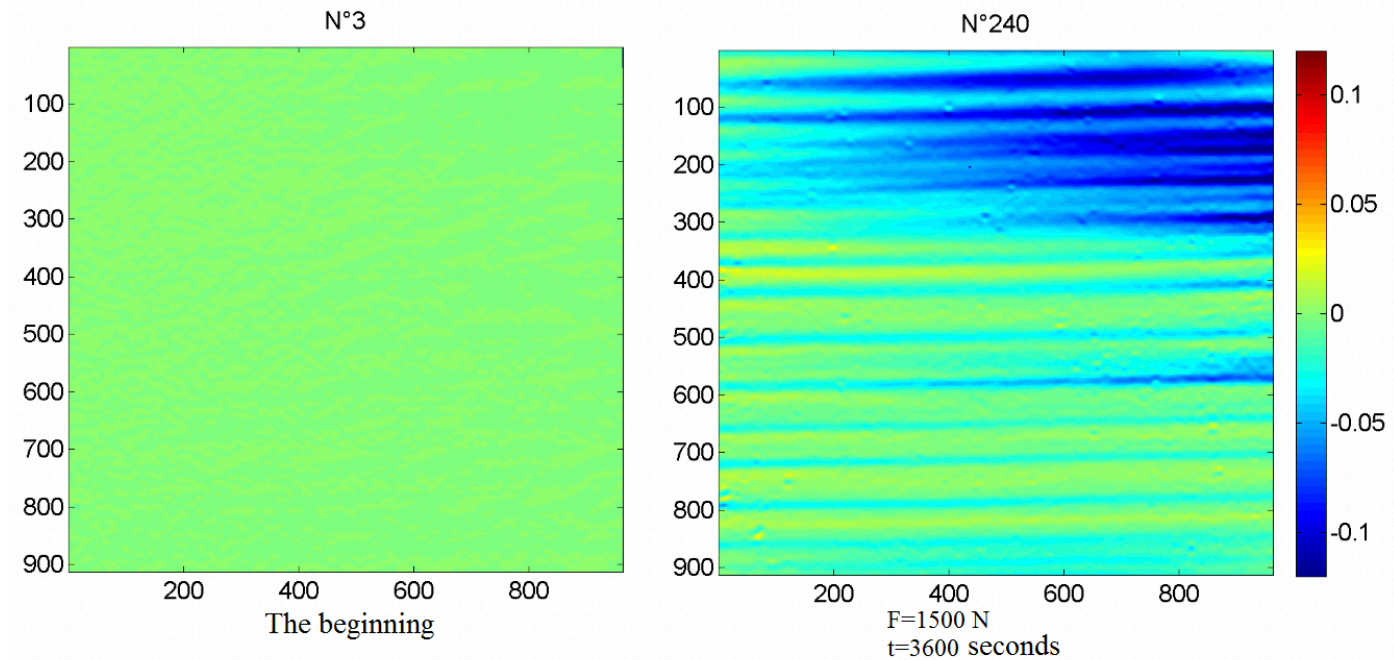

Figure 14: Radial strain maps without hydromechanical history during the creep phase of cycle 1 

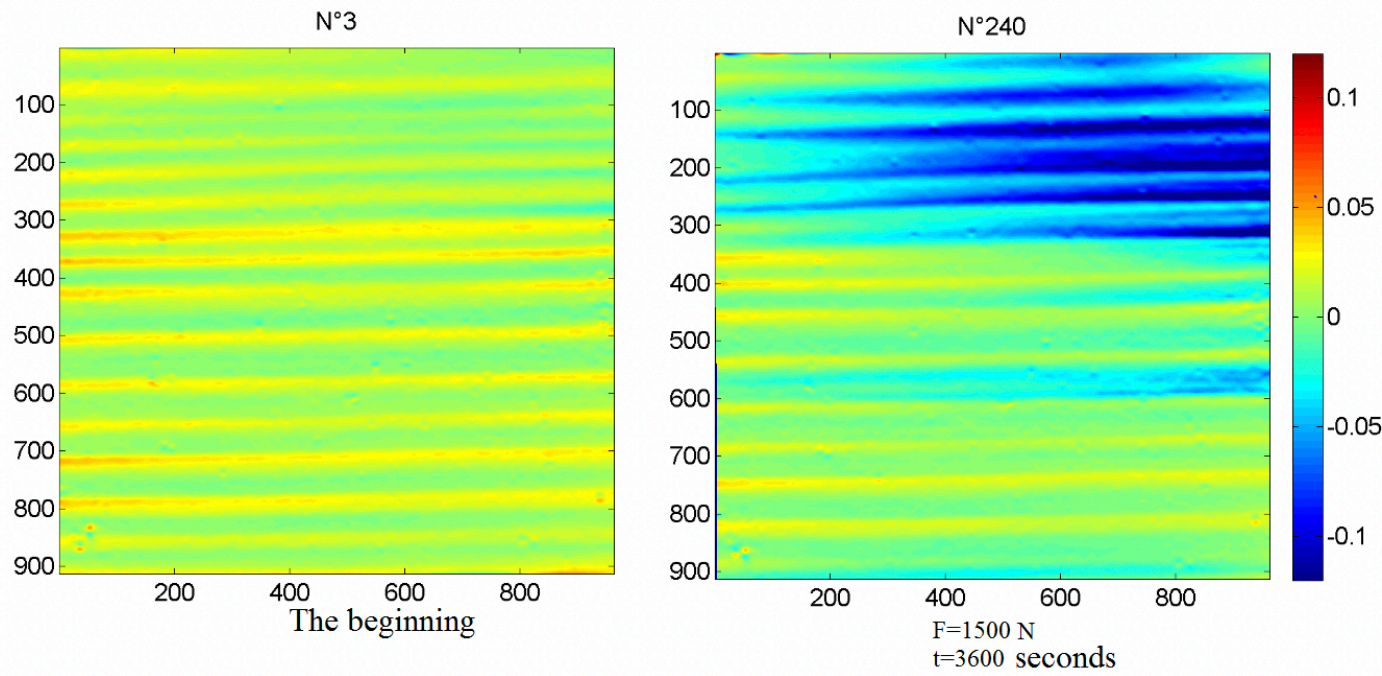

Figure 15: Radial strain maps including hydromechanical history during the creep phase of cycle 2

This thresholding procedure is applied to each cycle of Experiment 3. The masks obtained enable us to extract, from all the strain maps, the strains in $E W$ and $L W$ in each defined zone of interest. Note that the zone of interest and the thresholding bounds were nearly the same for each cycle. The creep phase for each cycle (see Figure 19-a) exhibits a strain level in $E W$ which is greater than in $L W$. This remark is in agreement with literature data. Indeed, microscopic observation reveals that the size of the lumens in $E W$ is greater, and that the thickness of the tracheids is smaller, than in $L W$ (Dang et al. (2017)).
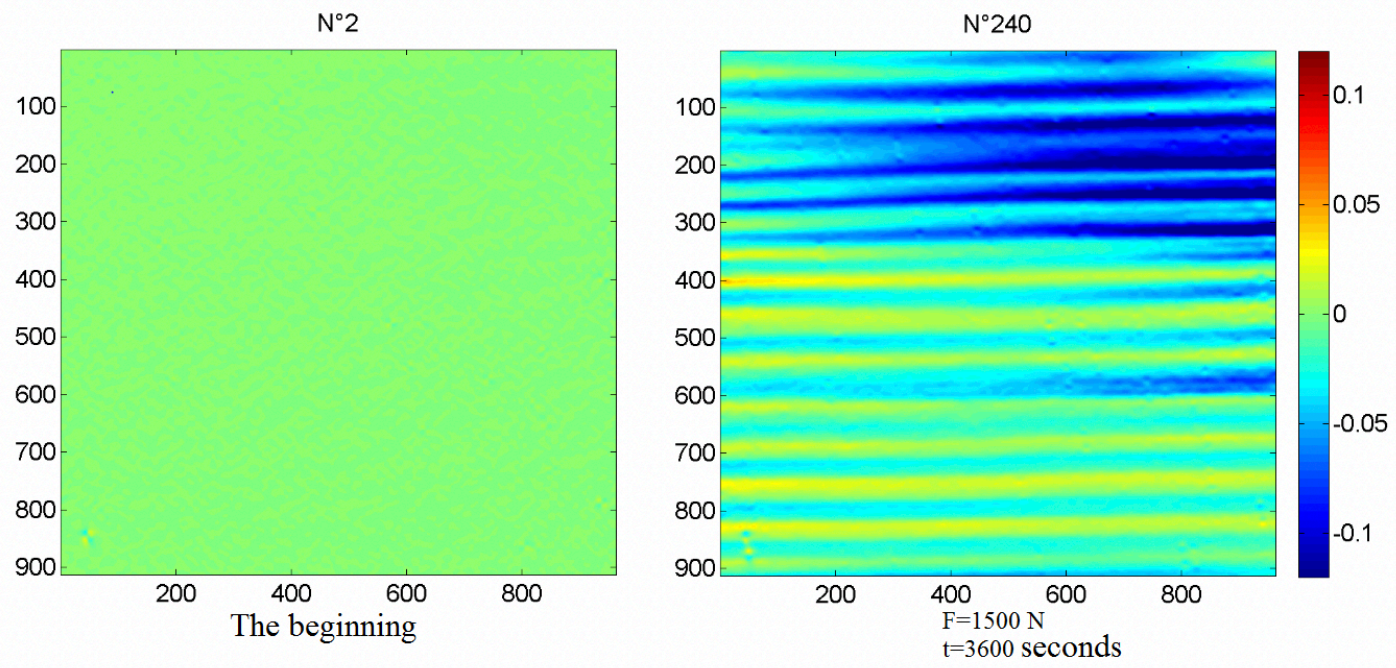

Figure 16: Radial strain maps without hydromechanical history during the creep phase of cycle 2 

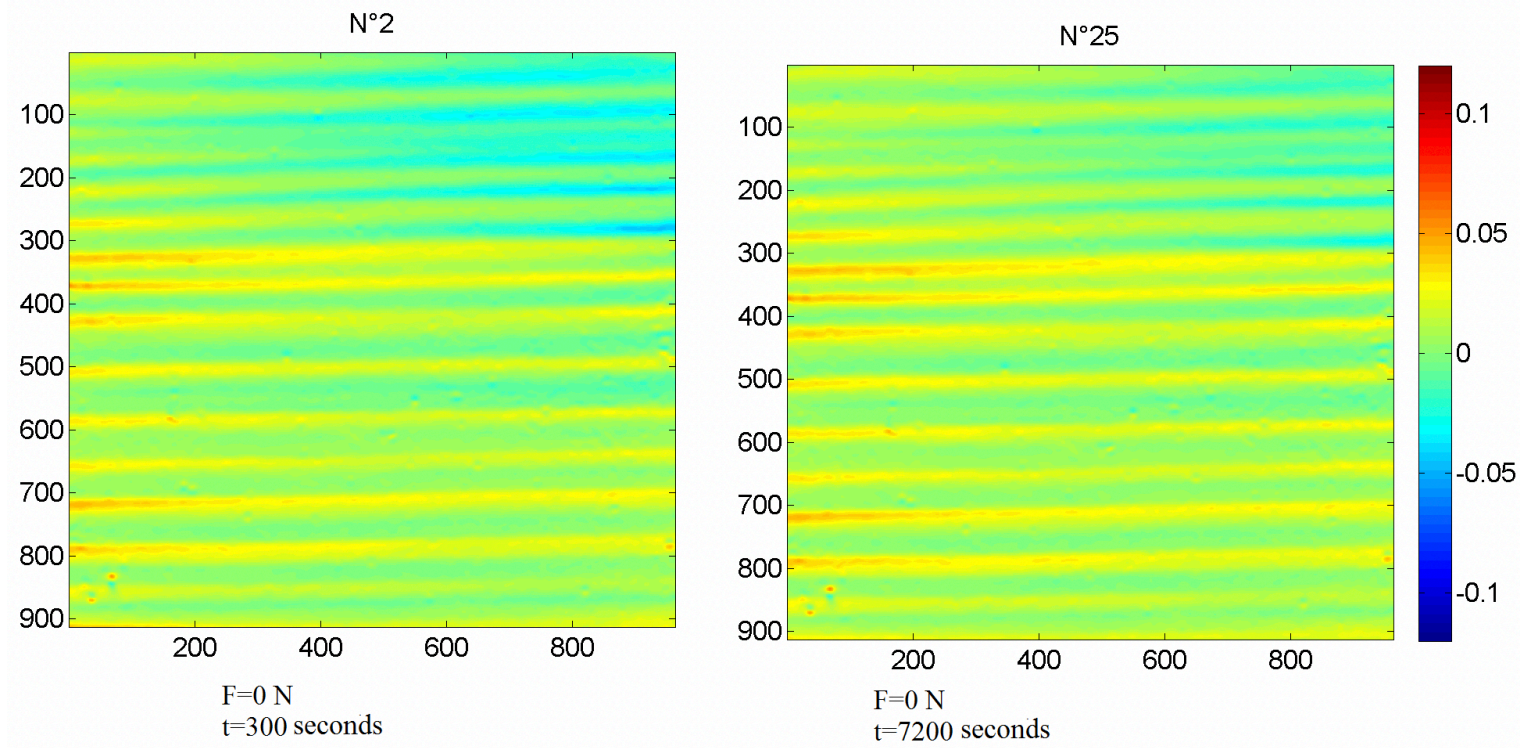

Figure 17: Radial strain maps including hydromechanical history during the recovery phase of cycle 2.

The recovery phase (unloaded state) shows a higher level of unrecovered strain from one cycle to the next. This can be explained by the viscoelastic nature of the material, combined with the effects of changes in $M C$. In addition, the slope of the strain curve during the creep phase progressively decreases with each cycle. A possible explanation for this observation is the lower variation in $M C$ and its effects due to the presence of mechanical loading. Note also that the material becomes stiffer during drying, which makes it less deformable when the drying process becomes more pronounced.

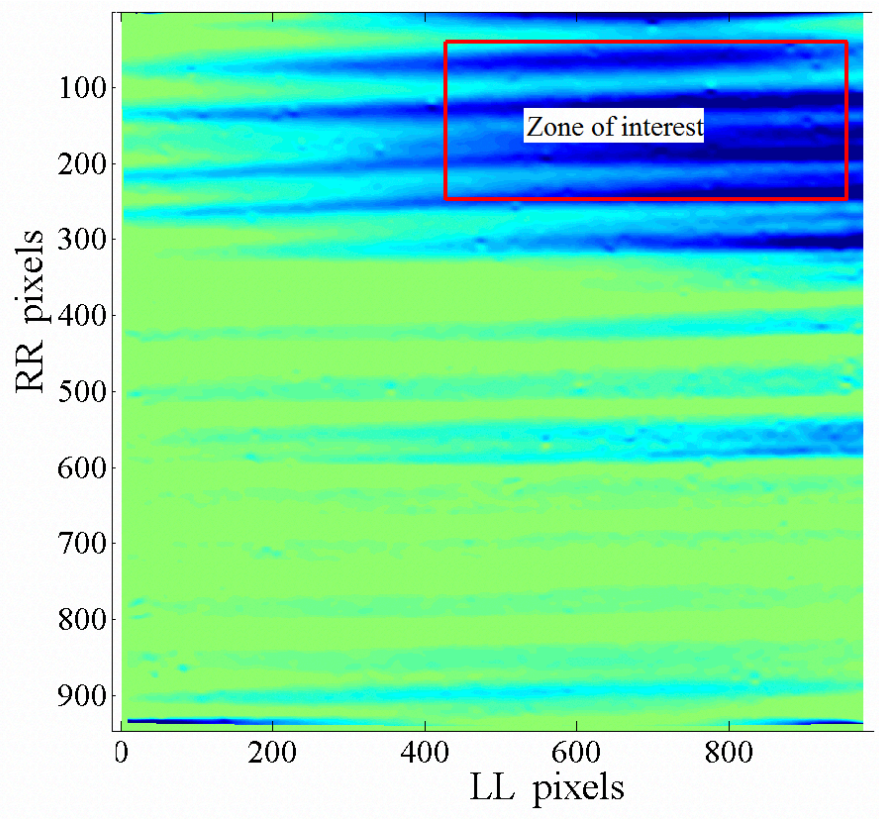

Figure 18: Zone of interest, cycle $1\left(S_{3}\right)$ 


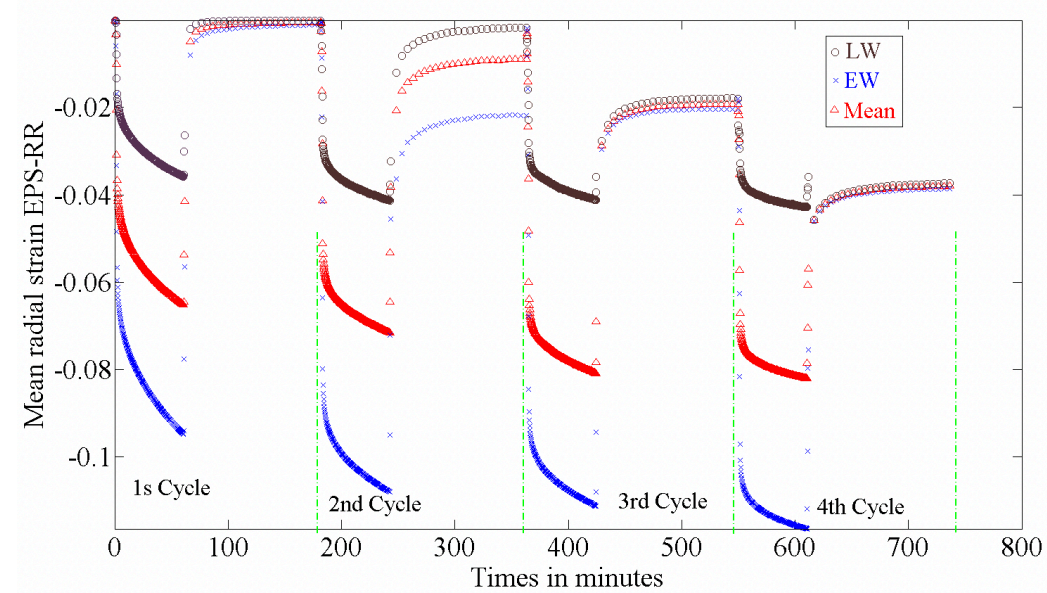

a)-Mean radial strain with hydromechanical history during creep/recovery cycles

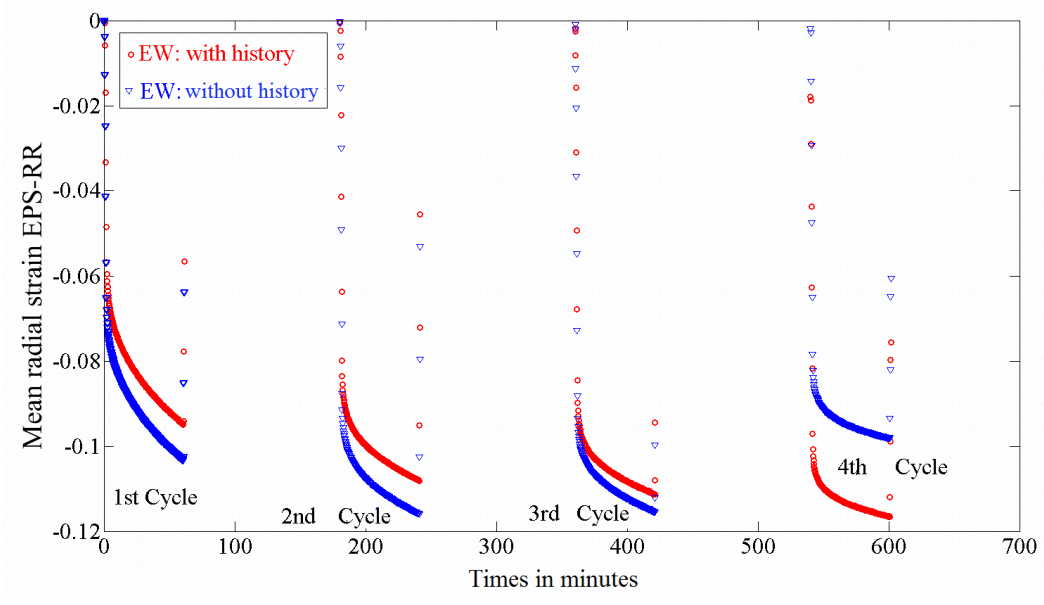

b)-Effects of hydromechanical history during creep/recovery cycles for EW

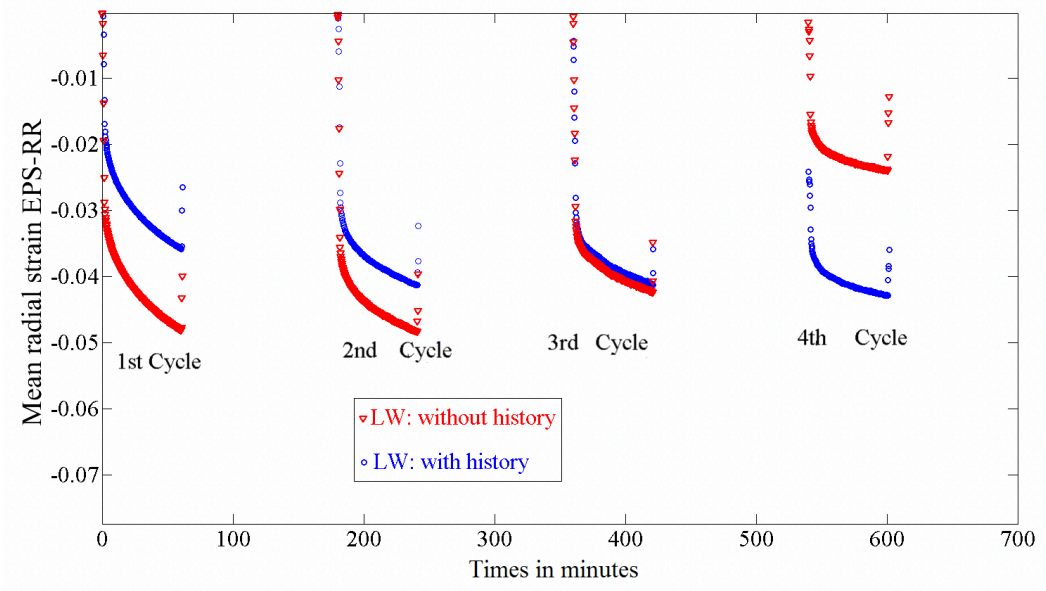

c)-Effects of hydromechanical history during creep/recovery cycles for LW

Figure 19: Mean radial strain during creep/recovery cycles $\left(S_{3}\right)$

In Figure 19-b, changes in the mean radial strain in $E W$ are presented for each creep phase and for each cycle, with and without the previous hydromechanical history of the sample. During the creep phase of the first three cycles, the mean radial strain without taking creep history into account is 
greater. A reduction in its deviation from that obtained when considering the history in the third cycle is observed. In the fourth cycle, the creep strain without considering the past hydromechanical history becomes lower. The decrease in strain when the history is ignored shows that $E W$ becomes stiffer. The inversion of the curves from the fourth cycle is a consequence of the increase in rigidity of $E W$. In this response, where the effect of mechanical loading is predominant, the amplitude decreases. The decrease in the slope over successive cycles is also a consequence of variations in mechanical properties. Changes in the mean radial strain in $L W$ are also shown for each creep phase and for each cycle in Figure 19-c. As in the case of $E W$, the curves are shown with and without the previous hydromechanical history. The mean radial strain without taking creep history into account is greater for the first three cycles, as in the case of $E W$. In addition, a reduction in its deviation from the mean radial strains obtained when considering the past hydromechanical history of the third cycle is observed. As for $E W$, the remark is the same at the fourth cycle for the same reasons. Indeed, $L W$ loses its flexibility during the drying process.

\section{Conclusions}

Radial strain maps during natural drying under creep/recovery were studied in this paper. A fullfield measurement technique, namely the grid method, was used for this purpose. Three experiments were performed. The response in terms of strain illustrated the spatial and local variability of the mechanical properties of wood. The results also highlighted the difference in terms of strain level between $E W$ and $L W$ during creep/recovery cycles. During Experiments 1 and 2, positive strain appeared mainly in $L W$. With Experiment 3, we found that the origin of this strain was due to the immersion phase. For all the experiments, the strain level observed during creep/recovery was more pronounced in $E W$. The third experiment enabled us to investigate the $M C$ effects on strain profiles by comparing strain maps with and without all the past hydromechanical history. A procedure of strain extraction at the growth ring scale was also implemented in order to build masks. These enabled the investigation of the hydromechanical behavior of wood at the ring scale both for $E W$ and for $L W$. It was also possible to highlight the effects of the previous hydromechanical history on the creep/recovery behavior of $E W$ and $L W$. Indeed, we highlighted the increase in stiffness of $E W$ and $L W$ by evidencing the reduction in the slope of the curve and by showing that the curves were progressively inversed.

In future studies, it will be interesting to develop an experimental device to apply mechanical loading/unloading, and to obtain the moisture content in real time. This experimental device should also integrate the full-field measurement technique and a system suitable for hygrothermal condition monitoring. Such an experimental device will enable much longer periods for creep/recovery cycles without losing any information in terms of moisture content loss or gain and in terms of deformation. The strain obtained, coupled with rheological models, should allow us to 
partition the total strain in order to isolate the thermo-visco-hydro-mechanosorptive effects. Furthermore, inverse methods should be established to identify the mechanical properties of the $E W$ and $L W$ of resinous woods such as Abies alba Mill.

\section{Appendix A: supplementary data}

The online version of this article contains examples of videos showing the strain variation during creep for each experiment.

\section{Acknowledgments}

The authors would like to thank Auvergne Promobois for providing the test specimens.

\section{References}

Armstrong, L. D. \& Christensen, G. N. (1961), 'Influence of moisture changes on deformation of wood under stress', Nature 191, 869-870.

Armstrong, L. D. \& Kingston, R. S. T. (1962), 'The effect of moisture content changes on the deformation of wood under stress', Australian journal of applied science 13(4), 257-276.

Armstrong, L. D., Kingston, R. S. et al. (1960), 'Effect of moisture changes on creep in wood.', Nature, London 185(4716), 862-3.

Badulescu, C., Grédiac, M. \& Mathias, J. D. (2009), 'Investigation of the grid method for accurate in-plane strain measurement', Measurement Science and Technology 20(9), 095102.

Cave, I. D. (1997), 'Theory of x-ray measurement of microfibril angle in wood', Wood Science and Technology 31(4), 225-234.

Cramer, S., Kretschmann, D., Lakes, R. \& Schmidt, T. (2005), 'Earlywood and latewood elastic properties in loblolly pine', Holzforschung 59(5), 531-538.

Dang, D., Moutou Pitti, R., Toussaint, E. \& Grédiac, M. (2014), Experimental evidence of water diffusion gradient in wood using the grid method. Final Cost Action FP0904 Conference.

Dang, D., Moutou Pitti, R., Toussaint, E. \& Grédiac, M. (2017), 'Inverse identification of earlyand latewood hydric properties using full-field measurements', Wood Material Science and Engineering .

Dang, D., Toussaint, E., Moutou Pitti, R. \& Grédiac, M. (2016), Investigation of the hydric transfer phenomenon in wood at the ring scale with the grid method, in 'Experimental and Applied Mechanics, Volume 4', Springer, pp. 77-81.

Dubois, F. (1997), The mechanical behaviour of crack viscoelastic media applied to wood material, $\mathrm{PhD}$ thesis, University of Limoges, France.

Freyburger, C., Longuetaud, F., Mothe, F., Constant, T. \& Leban, J.-M. (2009), 'Measuring wood density by means of x-ray computer tomography', Annals of Forest Science 66(8), 804. 
Gauvin, C., Jullien, D., Doumalin, P., Dupré, J. C. \& Gril, J. (2014), 'Image correlation to evaluate the influence of hygrothermal loading on wood', Strain 50(5), 428-435.

Grediac, M., Sur, F. \& Blaysat, B. (2016), 'The grid method for in-plane displacement and strain measurement: A review and analysis', Strain 52(3), 205-243.

Gril, J. (1988), Une modélisation du comportement hygro-rhéologique du bois à partir de sa microstructure, PhD thesis, Paris 6 University, France.

Hunt, D. G. (1984), 'Creep trajectories for beech during moisture changes under load', Journal of Materials Science 19(5), 1456-1467.

Hunt, D. G. (1989), 'Linearity and non-linearity in mechano-sorptive creep of softwood in compression and bending', Wood Science and Technology 23(4), 323-333.

Marčok, M., Kudela, J. \& Čunderlík, I. (1996), 'Identification of reaction beech wood by x-ray computed tomography', European Journal of Wood and Wood Products 54(2), 97-98.

Méité, M., Dubois, F., Pop, O. \& Absi, J. (2013), 'Mixed mode fracture properties characterization for wood by digital images correlation and finite element method coupling', Engineering Fracture Mechanics 105, 86-100.

Merakeb, S. (2006), Modeling of the timber structures in variable environment, $\mathrm{PhD}$ thesis, University of Limoges, France.

Moutee, M. (2006), Modeling of the mechanical behaviour of wood during drying, PhD thesis, Laval University, Canada.

Moutou Pitti, R. (2008), Découplage des modes mixtes de rupture dans les matériaux viscoélastiques orthotropes: modélisation et expérimentation, $\mathrm{PhD}$ thesis, Université de Limoges, France.

Peck, E. C. (1933), 'Specific gravity and related properties of softwood lumber', Washington: US Dept. of Agriculture.URL:https://naldc.nal.usda.gov/naldc/download.xhtml?id=CAT86200337 content $=\mathrm{PDF}$

Pereira, J., Xavier, J., Morais, J. \& Lousada, J. (2013), ‘Assessing wood quality by spatial variation of elastic properties within the stem: Case study of pinus pinaster in the transverse plane 1', Canadian Journal of Forest Research 44(2), 107-117.

Piro, J. L. \& Grédiac, M. (2004), 'Producing and transferring low-spatial-frequency grids for measuring displacement fields with moiré and grid methods', Experimental Techniques 28(4), 2326. Society for Experimental Mechanics.

Pittet, V. (1996), Etude expérimentale des couplages mécanosorptifs dans le bois soumis à variations hygrométriques contrôlées sous chargements de longue durée, PhD thesis, École polytechnique fédérale de Lausanne, Suisse.

Pop, O., Meite, M., Dubois, F. \& Absi, J. (2011), 'Identification algorithm for fracture parameters by combining dic and fem approaches', International journal of fracture 170(2), 101-114.

Randriambololona, H. (2003), Modélisation du comportement différé du bois en environnement variable $\mathrm{PhD}$ thesis in Civil Engineering, Université de Limoges, France.

Sahlberg, U., Salmén, L. \& Oscarsson, A. (1997), 'The fibrillar orientation in the s2-layer of wood 
fibres as determined by x-ray diffraction analysis', Wood Science and Technology 31(2), 7786.

Saifouni, O. (2014), Modeling of rheological effects in materials : application to the mechanosorptive behaviour of wood, Phd thesis, University of Blaise Pascal - Clermont-Ferrand II. URL: https://tel.archives-ouvertes.fr/tel-01069026

Saifouni, O., Destrebecq, J.-F., Froidevaux, J. \& Navi, P. (2016), 'Experimental study of the mechanosorptive behaviour of softwood in relaxation', Wood Science and Technology 50(4), 789-805.

Sanabria, S. J., Lanvermann, C., Michel, F., Mannes, D. \& Niemz, P. (2015), 'Adaptive neutron radiography correlation for simultaneous imaging of moisture transport and deformation in hygroscopic materials', Experimental Mechanics 55(2), 403-415.

Silva, F., Morais, J., Dourado, N., Xavier, J., Pereira, F. \& de Moura, M. (2014), 'Determination of cohesive laws in wood bonded joints under mode ii loading using the ENF test', International Journal of Adhesion and Adhesives 51, 54-61.

Tanaka, T., Avramidis, S. \& Shida, S. (2009), 'Evaluation of moisture content distribution in wood by soft X-ray imaging', Journal of wood science 55(1), 69-73.

Watanabe, U., Norimoto, M., Fujita, M. \& Gril, J. (1998), 'Transverse shrinkage anisotropy of coniferous wood investigated by the power spectrum analysis', Journal of Wood Science 44(1), 9-14.

Xavier, J., Oliveira, M., Monteiro, P., Morais, J. J. L. \& de Moura, M. F. S. F. (2014), 'Direct evaluation of cohesive law in mode 1 of pinus pinaster by digital image correlation', Experimental Mechanics 54(5), 829-840. 